\title{
TEORES ELEVADOS DE METAIS POTENCIALMENTE TÓXICOS EM AMOSTRAS DE FERTILIZANTES
}

\author{
Ellen Del Maschio Mallagoli ${ }^{1}$
}

Flávio Fernando Manzini ${ }^{2}$

\section{Lídia Maria de Almeida Plicas ${ }^{3}$}

Resumo: A contaminação do solo por metais potencialmente tóxicos constitui um dos principais problemas ambientais. Por meio da lixiviação e percolação das águas, esses metais podem ser mobilizados e vir a contaminar mananciais superficiais e subterrâneos, comprometendo sua qualidade. A biodisponibilização desses metais para as plantas e, a partir dessas, para o homem é outro desfecho negativo dessa situação. O cádmio é um elemento tóxico. Os teores encontrados nos solos costumam não oferecer riscos. Porém, esses teores são potencializados pela utilização de fertilizantes. O níquel pode ser carcinogênico em doses elevadas. Sua presença em fertilizantes fosfatados proporciona maiores concentrações do metal no solo. É amplo o registro sobre efeitos do excesso desses metais, tanto em plantas, quanto em animais e no ser humano. O manganês é um dos elementos mais abundantes na crosta terrestre e se encontra largamente distribuído em solos, sedimentos, rochas, água e materiais biológicos. Contrariamente aos dois metais anteriores, esse micronutriente é um elemento essencial ao ser humano. Sua carência causa inúmeras enfermidades, por outro lado, seu excesso também. Nesse caso, poucos são os relatos sobre o assunto. Nesse estudo foram utilizados métodos de

\footnotetext{
${ }^{1}$ Bacharel em Ciências Biológicas, Instituto de Biociências, Letras e Ciências Exatas, UNESP-SP ellenmalagoli@hotmail.com

${ }^{2}$ Doutor em Geologia Regional, Instituto de Biociências, Letras e Ciências Exatas, UNESP-SP fmanzini@ibilce.unesp.br

${ }^{3}$ Doutora em Físico-Química, Instituto de Biociências, Letras e Ciências Exatas, UNESP-SP plicas@ibilce.unesp.br
} 
extração de metais de fertilizantes e se constatou que, quando presentes, os metais cádmio e níquel apresentaram concentrações proibitivas o que é motivo de preocupação e demonstra a falta de controle sobre a indústria de insumos agrícolas. Para o manganês não há parâmetros orientadores com limites de teores, mas com certeza, são necessários trabalhos nesse sentido para se evitar seu consumo indiscriminado.

Palavras-chave: análises químicas, fertilizantes, metais potencialmente tóxicos

\section{INTRODUÇÃO}

Os metais potencialmente tóxicos, termo mais difundido para metais pesados, são aqueles que apresentam alta densidade (> $5 \mathrm{~g} \mathrm{~cm}^{-3}$ ), em comparação aos demais elementos e número atômico maior que 20. Dentre eles, o mercúrio $(\mathrm{Hg})$, chumbo $(\mathrm{Pb})$, cádmio (Cd) e arsênio (As) são os de maior risco ambiental em razão do seu uso intenso, toxicidade e ampla distribuição. Estes metais são resistentes à degradação e podem se acumular nos componentes em que manifestam sua toxicidade. Os locais de fixação final dos metais pesados são os solos e sedimentos (MANZINI et al., 2010 e BAIRD, 2002). Esses metais estão, naturalmente, presentes nas rochas e nos solos, desde o seu processo de formação. Atualmente Devido ao incremento do uso de corretivos e fertilizantes agrícolas, de produtos como lodo de esgoto, compostos de lixo urbano e resíduos de indústria ou mineração e, também, da utilização de água de irrigação contaminada, os solos apresentam maiores concentrações desses metais, que podem ser transferidos para a cadeia alimentar dos animais e do homem (FIGUEIREDOFERNANDES et al., 2007). Os graus de mobilidade, atividade e biodisponibilidade desses metais no solo dependem de fatores, como $\mathrm{pH}$, temperatura, potencial redox, CTC, competição com outros metais, ligação com ânions, composição e força iônica da solução do solo (OLIVEIRA e COSTA, 2004).

O cádmio é um elemento de número atômico 48 e símbolo Cd. É um metal pertencente ao grupo 2B (transição) da Tabela Periódica, sendo relativamente raro, e não encontrado em estado puro, mas associado, preferencialmente a sulfitos, minérios de zinco, chumbo e cobre (WHO,1992 apud CARDOSO e CHASIN, 2001). Apresenta-se nas 
cores prata, azulado ou metálico. Sua consistência é friável. Sua abundância é de cerca de 0,1 a 0,2 ppm na crosta terrestre (ATSDR, 1997 e MEDITEXT, 2001 apud CARDOSO e CHASIN, 2001). Esse metal é, normalmente, utilizado em tintas e na confecção de ligas metálicas. Cigarros, farinhas refinadas, materiais odontológicos, indústria de aço, emissões gasosas industriais, fertilizantes, pesticidas, fungicidas, materiais cerâmicos, frutos do mar, farinha de ossos, solda e pilhas elétricas são algumas das fontes de cádmio. Há ocorrência de cádmio em toda crosta terrestre, em concentração média de 0,1 $\mathrm{mg} \mathrm{kg}^{-1}$. Rochas sedimentares e fosfatos marinhos podem apresentar concentrações do metal, que chegam a $15 \mathrm{mg} \mathrm{kg}^{-1}$, valor considerado muito alto. Áreas de depósitos de minérios de zinco, chumbo e cobre, apresentam altas concentrações de cádmio, sendo essas as regiões mais propícias à contaminação do solo e da água. O lançamento de cádmio na atmosfera se dá, principalmente, por atividades vulcânicas, tanto de baixa, quanto de alta intensidade, pelos incêndios florestais e pela queima de combustíveis fósseis (WHO,1992 apud CARDOSO e CHASIN, 2001, ATSDR apud MANZINI et al., 2010). Seu fumo, liberado quando aquecido a altas temperaturas, é altamente tóxico. As formas de absorção do metal pelo corpo humano são a respiração de fumaça de cigarro, a ingestão de água e alimentos ou de partículas suspensas no ar. Não há relatos de que o cádmio possa ser absorvido pela pele (ATSDR apud MANZINI et al., 2010). As manifestações conhecidas provocadas pela intoxicação pelo elemento são a elevação da pressão sanguínea e aumento do coração, a queda da imunidade, o aumento da próstata, - enfraquecimento ósseo, dores nas articulações, anemia, enfisema pulmonar, osteoporose, perda de olfato e perda do desempenho sexual (CARDOSO e CHASIN, 2001, GUERREIRO, 2007). O metal é facilmente absorvido pelos vegetais, por isso, entra na cadeia alimentar. Quando adsorvido ao solo, seu teor biodisponível diminui. Não é considerado um elemento essencial ao corpo e, não é requerido, mesmo que em baixas concentrações. Considerado persistente, acumula-se nos rins e fígado dos mamíferos, podendo provocar irritações no estômago, vômitos, diarréia, além de enfraquecer os ossos e levar à morte. Estudos mostram que houve danos ao cérebro e ao sistema nervoso, em mamíferos submetidos ao metal. Não se sabe ainda os efeitos que ele causa ao feto. Em plantas, diminui o potencial de absorção de nutrientes (SANITÀ di TOPPI e GABBRIELLI, 1999 e LEITA et al., 1995 apud GONÇALVES et al. 2008). Por não se saber a concentração mínima para todos esses efeitos, a Agência Internacional para a 
Pesquisa do Câncer (IARC) considera o cádmio como um elemento carcinogênico ao ser humano (ATSDR apud MANZINI et al., 2010).

O níquel é um elemento de número atômico 28 e símbolo Ni. É um metal pertencente ao grupo 8B (transição) da Tabela Periódica. É o 24 metal em abundância na crosta terrestre e sua fonte mais importante são os minérios na forma de sulfeto de níquel. É utilizado, principalmente, na produção de ligas, na indústria de galvanoplastia, na fabricação de baterias (baterias de $\mathrm{Ni}-\mathrm{Cd}$ ), em produtos a base de petróleo, em pigmentos, como catalisadores, em utensílios de cozinha, jóias, cosméticos, óleos hidrogenados e soldas (McGRATH e SMITH, 1990 e MOORE e RAMAMOORTHY, 1984 apud SCOTTON, 2011). Sua alta concentração no solo se deve a atividades antropogênicas, como a utilização de fertilizantes fosfatados, a queima de combustíveis e óleos, a combustão de carvão, a mineração, a aplicação de resíduos como lodo no solo e a fundições (McGRATH \& SMITH, 1990 e MALAVOLTA, 1994 apud SCOTTON, 2011). A exposição a esse metal e seus compostos solúveis não deve ser superior a $0,05 \mathrm{mg} \mathrm{cm}^{-3}$. O níquel é considerado um elemento carcinogênico às vias respiratórias dos seres humanos, sendo que a exposição ocupacional ao metal pode conduzir ao desenvolvimento de câncer nasal, de pulmão e de laringe (CASARETT e DOULL'S, 1996 apud SCOTTON, 2011).

O manganês é um elemento químico, de símbolo $\mathrm{Mn}$, com número atômico 25 e sólido em temperatura ambiente. É um metal de transição do grupo 7 da tabela periódica. Como os demais elementos de transição, possui algumas propriedades características: apresenta várias formas e estados de oxidação $(0 \mathrm{a}+7)$ e pode formar vários compostos coloridos e paramagnéticos. É um metal que se apresenta sólido, frágil e quebradiço sendo, facilmente, oxidável. É o terceiro metal mais abundante na crosta terrestre, depois do alumínio e do ferro estando amplamente distribuído (MARTINS \& LIMA, 2001 apud MANZINI et al, 2010). É um elemento natural que se encontra facilmente nas rochas. Não ocorre em sua forma pura. Ocorre combinado com outros elementos como o oxigênio, enxofre e cloro. Estes compostos são sólidos que não se evaporam. Pequenas partículas de pó desse material sólido podem existir suspensas no ar e, além disso, alguns compostos podem dissolver-se na água sendo detectados, por vezes, baixos teores dos mesmos em lagos, riachos e oceanos. É encontrado em centenas de minerais, embora apenas uma dezena apresente interesse comercial. Destacam-se: pirolusita $\left(\mathrm{MnO}_{2}\right)$, 
psilomelano $\left(\mathrm{MnO}_{2} \cdot \mathrm{H}_{2} \mathrm{O}\right)$, manganita $(\mathrm{MnO}(\mathrm{OH}))$, braunita $\left(3 \mathrm{Mn}_{2} \mathrm{O}_{3} \cdot \mathrm{MnSiO}_{3}\right)$, rodonita $\left(\mathrm{MnSiO}_{3}\right)$, rodocrosita $\left(\mathrm{MnCO}_{3}\right)$, hübnerita $\left(\mathrm{MnWO}_{4}\right)$, entre tantos. Também ocorre no leito marinho, na forma de nódulos, onde o conteúdo de manganês oscila entre 15 a 30\%. Há possibilidade de aproveitamento econômico dessa forma de ocorrência. Os compostos de manganês podem ser classificados em orgânicos e inorgânicos. Entre as formas inorgânicas incluem-se as que se encontram nos produtos de combustão no escapamento de automóveis ou caminhões e nos pós que estão presentes na produção de aço ou baterias. As formas orgânicas de manganês são, principalmente, os aditivos para a gasolina e para os praguicidas (MARTINS \& LIMA, 2001 e ATSDR apud MANZINI et al., 2010).

Os seres humanos estão expostos ao manganês nos alimentos, na água que ingerem e no ar que respiram. As crianças amamentadas ingerem manganês presente no leite materno, em fórmulas infantis a base de soja ou em leite de vaca. O manganês é essencial à manutenção da vida. Sua carência, nos humanos, pode causar perda de peso, fragilidade óssea, dermatite, degeneração do ovário ou testículos e náuseas (ATSDR apud MANZINI et al., 2010). Seu excesso pode causar dermatite, diminuição dos fatores coagulantes dependentes da vitamina $\mathrm{K}$, aumento dos níveis sanguíneos de cálcio, fósforo e fosfatase alcalina (podendo este último fator ser indicativo de uma remodelação óssea), infertilidade, diminuição do metabolismo da glucose, diminuição do metabolismo proteico, diminuição do crescimento e distúrbios ao nível do esqueleto, aterosclerose, disfunção pancreática, aumento da pressão sanguínea, redução da função imune, ataxia, deficiência de selênio, depressão da atividade das glândulas mamárias e anormalidades nas mitocôndrias (DAMIÃO \& RAMOS, 2004/2005).

Estudo realizado por Menezes Filho (2009), na Vila de Cotegipe, Município de Simões Filho, no Estado da Bahia, demonstrou que a comunidade se encontra exposta a níveis de concentração elevada de manganês o que tem afetado, em especial, as crianças que apresentam desempenho intelectual deficiente. Existe, ainda, a hipótese de que esta dosagem influencie no desenvolvimento das crianças via transferência maternofetal. Esta situação de contaminação é proporcionada por emissões atmosféricas da Companhia Rio Doce Manganês (RDM), uma metalúrgica de ligas ferro-manganês. Este metal tem uma meia-vida curta, em média 36 dias, que depende da ingestão e da carga corpórea de manganês, enquanto que no cérebro a meia-vida é consideravelmente mais 
longa do que no corpo como um todo. Portanto, numa situação de absorção excessiva, o manganês pode se acumular no cérebro. $O$ aumento da concentração do metal no cérebro pode dar início a danos neuronais, resultando em diminuição no número de neurônios dopaminérgicos. Macacos expostos cronicamente ao elemento, por meio de injeção intravenosa ou por inalação, apresentaram significativos decréscimos na função cognitiva e alterações comportamentais compatíveis com transtorno compulsivo.

Quanto ao manganês liberado por meio de produtos de combustão e/ou na forma de aditivos aos combustíveis (no caso, MMT - Metilciclopentadienil tricarbonil manganês, um aditivo antidetonante da gasolina) não existem relatos (LORANGER et al,1996 apud. MARTINS e LIMA, 2001).

Os fertilizantes e outros insumos agrícolas podem conter elementos provenientes da rocha de origem ou até mesmo do seu processo de industrialização. As rochas fosfatadas contêm a maior concentração de cádmio. O efeito dessa adição indireta de cádmio pode ser observado depois de décadas (McBRIDE e SPIERS, 2001 apud CAMPOS et al., 2005). O fosfato é vital para o desenvolvimento dos seres vivos. Nas plantas, por exemplo, o fósforo é necessário para a fotossíntese, respiração e reprodução, porém, quando aplicados os fertilizantes fosfatados às culturas, apenas $10 \%$ são absorvidos pelos vegetais (STAUFFER e RAIJ, 2003 apud CAMPOS et al., 2005).

Atualmente, há uma preocupação com o uso desses fertilizantes e, até mesmo, com águas de irrigação provenientes de afluentes contaminados, ou lodos de tratamento biológico, pois, na maioria das vezes, são utilizados em culturas para alimentação humana (ALCARDE e RODELLA, 2003 apud CAMPOS et al., 2005). Por isso, é de fundamental importância o conhecimento das concentrações dos metais pesados existentes nesses insumos (CAMPOS et al., 2005).

Diante do relato acima, o propósito desse estudo foi o de se quantificar os teores dos metais cádmio, níquel e manganês presentes em insumos agrícolas, no caso, fertilizantes comerciais.

\section{DESENVOLVIMENTO}

\section{Materiais, equipamentos e metodologias}




\subsection{Materiais e equipamentos}

Os materiais utilizados neste projeto foram:

- 8 amostras de fertilizantes, sendo 4 de composição NPK (amostras 3, 6, 7

e 8) e 4 com misturas minerais não especificadas (amostras 1, 2, 4 e 5)

- vidrarias apropriadas e material de filtragem

- reagentes de grau analítico, água destilada

Os equipamentos utilizados em laboratório foram:

- peneira para granulometria com abertura de malha 0,15mm (ABNT 100)

- balança analítica OWA Labor

- bloco digestor MARCONI MA4025

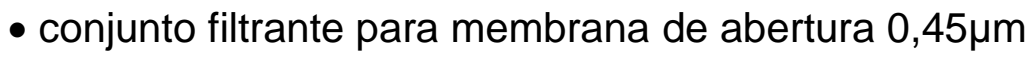

- espectrômetro de absorção atômica (EAA) por atomização em chama modelo Varian SpectrAA 50B

\subsection{Metodologias de extração e determinação}

Inicialmente, as amostras de fertilizantes foram desagregadas de tal modo a passarem por peneira com abertura $0,15 \mathrm{~mm}$ (SILVA, 2009). Foram, então, submetidas a dois métodos de extração: método 1, por ácido clorídrico ( $\mathrm{HCL}$ ) concentrado, a quente e método 2, pela combinação entre os ácidos nítrico $\left(\mathrm{HNO}_{3}\right)$ e clorídrico, concentrados, a quente e peróxido de hidrogênio $\left(\mathrm{H}_{2} \mathrm{O}_{2}\right)$ a $30 \%$. O método 1 se mostrou mais eficaz na extração de manganês. $O$ método 2 foi mais apropriado para a extração dos metais níquel e cádmio. As análises foram feitas em triplicata.

\subsubsection{Extração e determinação de manganês (método 1)}

Para se extrair o metal manganês dos fertilizantes e determinar a sua concentração, foram utilizadas metodologias disponíveis em Silva (2009).

Para a extração transferiu-se $1 \mathrm{~g}$ de cada amostra para béqueres de $150 \mathrm{~mL}$, adicionando-se $10 \mathrm{~mL}$ de $\mathrm{HCl}$ concentrado. Esse sistema foi submetido à fervura até próximo à secagem sem, contudo, deixar queimar o resíduo. 
A esse resíduo foram adicionados, então, $20 \mathrm{~mL}$ de solução de $\mathrm{HCl} 2 \mathrm{~mol} \mathrm{~L}^{-1} \mathrm{e}$ levado a ferver. Deixou-se esfriar e filtrou-se em filtro com membrana de 0,45 $\mu \mathrm{m}$ de abertura. $\mathrm{O}$ filtrado foi transferido para balão volumétrico de $100 \mathrm{~mL}$, completando-se o volume com água destilada. Os extratos assim obtidos foram reservados.

Os reagentes e soluções utilizados na determinação da concentração do metal foram:

- solução estoque padrão, rastreada, de manganês $1000 \mathrm{mg} \mathrm{L}^{-1}$ da marca MERCK

- solução padrão $50 \mathrm{mg} \mathrm{L}^{-1}$ : foram transferidos $5 \mathrm{~mL}$ da solução estoque para balão volumétrico de $100 \mathrm{~mL}$ e completado o volume com solução de $\mathrm{HCl} 0,5 \mathrm{~mol} \mathrm{~L}^{-1}$

- soluções padrão de trabalho: foram transferidas alíquotas de $0,0,25 \mathrm{~mL}$, $0,5 \mathrm{~mL}, 1,0 \mathrm{~mL}, 2,5 \mathrm{~mL}$ e $5,0 \mathrm{~mL}$ da solução padrão acima descrita para balões volumétricos de $50 \mathrm{~mL}$ e completado o volume com solução de $\mathrm{HCl}$ $0,5 \mathrm{~mol} \mathrm{~L}^{-1}$ obtendo-se, assim, as soluções padrão de trabalho branco/0,25/0,5/1,0/2,5/5,0 $\mathrm{mg} \mathrm{L}^{-1}$

Essas soluções foram processadas em espectrômetro de absorção atômica por atomização em chama, no comprimento de onda $279,5 \mathrm{~nm}$, obtendo-se as absorbâncias com as quais se elaborou a curva padrão.

Também foram processados, do mesmo modo, os extratos reservados, calculadas as concentrações e feitas as transformações para a unidade padrão de concentração, nesse caso $\mathrm{mg} \mathrm{kg}^{-1}$.

\subsubsection{Extração e determinação de cádmio e níquel (método 2)}

Para se extrair os metais cádmio e níquel dos fertilizantes e determinar a sua concentração, foi utilizado o método SW 846 - método 3050B, da Agência de Proteção Ambiental dos Estados Unidos da América (US-EPA), também disponível em Silva (2009).

Os reagentes e soluções utilizados na extração e na determinação da concentração dos metais foram:

- ácido nítrico concentrado (P.A)

- ácido clorídrico concentrado (P.A.) 
- peróxido de hidrogênio (30\%)

- solução estoque padrão, rastreada, de cádmio $1000 \mathrm{mg} \mathrm{L}^{-1}$ da marca GQ

- solução estoque padrão, rastreada, de níquel $1000 \mathrm{mg} \mathrm{L}^{-1}$ da marca GQ

- solução de ácido nítrico 1:1, preparada a partir da combinação entre água destilada e ácido nítrico concentrado, em partes iguais

De acordo com a metodologia empregada, transferiu-se $500 \mathrm{mg}$ de amostra de fertilizante para um béquer de $50 \mathrm{~mL}$ e $10 \mathrm{~mL}$ de solução de ácido nítrico 1:1. O béquer foi coberto com vidro de relógio e submetido a aquecimento em bloco digestor com controle de temperatura a $95^{\circ} \mathrm{C}$, sem ebulição, por 15 minutos.

Após o resfriamento, foram adicionados $5 \mathrm{~mL}$ de ácido nítrico concentrado e repetido o processo de aquecimento. Esse procedimento foi repetido até que se finalizasse a emissão de fumos marrons, indicando que a reação com o ácido nítrico havia se completado.

Foram adicionados $2 \mathrm{~mL}$ de água destilada e $3 \mathrm{~mL}$ de peróxido de hidrogênio. Tampou-se o béquer com vidro de relógio e manteve-se o sistema sob aquecimento a $95^{\circ} \mathrm{C}$. Repetiu-se o procedimento até que a aparência da amostra não mais se alterasse.

Foram adicionados, por fim, $5 \mathrm{~mL}$ de ácido clorídrico concentrado e $10 \mathrm{~mL}$ de água destilada. Cobriu-se, novamente, o béquer com vidro de relógio colocando-se o sistema sob aquecimento, sem fervura, por 15 minutos. Após o resfriamento filtrou-se em filtro com membrana de $0,45 \mu \mathrm{m}$ de abertura. $O$ filtrado foi transferido para balão volumétrico de $100 \mathrm{~mL}$, completando-se o volume com água destilada. Os extratos assim obtidos foram reservados.

Os reagentes e soluções utilizados na determinação da concentração dos metais foram:

- solução estoque padrão, rastreada, de cádmio $1000 \mathrm{mg} \mathrm{L}^{-1}$ da marca GQ - solução estoque padrão, rastreada, de níquel $1000 \mathrm{mg} \mathrm{L}^{-1}$ da marca GQ - solução intermediária $5 \mathrm{mg} \mathrm{L}^{-1}$ para o cádmio: foram transferidos $0,50 \mathrm{~mL}$ da solução estoque padrão de cádmio para balão volumétrico de $100 \mathrm{~mL}$ adicionando-se $10 \mathrm{~mL}$ de ácido nítrico concentrado e completando-se o volume com água destilada

- solução intermediária $5 \mathrm{mg} \mathrm{L}^{-1}$ para o níquel: foram transferidos $0,50 \mathrm{~mL}$ da solução estoque padrão de cádmio para balão volumétrico de $100 \mathrm{~mL}$ 
adicionando-se $10 \mathrm{~mL}$ de ácido nítrico concentrado e completando-se o volume com água destilada

- soluções padrão de trabalho para o cádmio: foram transferidas alíquotas de $0,0,10 \mathrm{~mL}, 0,25 \mathrm{~mL}, 0,50 \mathrm{~mL}, 1,00 \mathrm{~mL}$ e $5,00 \mathrm{~mL}$ da solução intermediária descrita para o cádmio para balões volumétricos de $50 \mathrm{~mL}$, acrescentados 5 $\mathrm{mL}$ de ácido nítrico concentrado, $5 \mathrm{~mL}$ de ácido clorídrico concentrado e completado o volume com água destilada obtendo-se, assim, as soluções padrão de trabalho branco/0,10/0,25/0,50/1,00/5,00 $\mathrm{mg} \mathrm{L}^{-1}$

- soluções padrão de trabalho para o níquel: foram transferidas alíquotas de $0,0,10 \mathrm{~mL}, 0,25 \mathrm{~mL}, 0,50 \mathrm{~mL}, 1,00 \mathrm{~mL}$ e $5,00 \mathrm{~mL}$ da solução intermediária descrita para o níquel para balões volumétricos de $50 \mathrm{~mL}$, acrescentados 5 $\mathrm{mL}$ de ácido nítrico concentrado, $5 \mathrm{~mL}$ de ácido clorídrico concentrado e completado o volume com água destilada obtendo-se, assim, as soluções padrão de trabalho branco/0,10/0,25/0,50/1,00/5,00 $\mathrm{mg} \mathrm{L}^{-1}$

Essas soluções foram processadas em espectrômetro de absorção atômica por atomização em chama, nos comprimentos de onda 228,8 nm, para o cádmio e 232,0 nm, para o níquel, obtendo-se as absorbâncias com as quais foram elaboradas as curvas padrão.

Também foram processados, da mesma maneira, os extratos reservados, calculadas as concentrações e feitas as transformações para a unidade padrão de concentração, nesse caso $\mathrm{mg} \mathrm{kg}^{-1}$.

\section{Resultados e discussões}

As concentrações obtidas para os metais manganês, cádmio e níquel das amostras de fertilizantes analisadas se encontram no Quadro 1.

Quadro 1. Concentrações de $\mathrm{Mn}, \mathrm{Cd}$ e Ni nas amostras de fertilizantes

\begin{tabular}{|c|c|c|c|}
\hline amostra & {$[\mathbf{M n}] \mathbf{~ m g ~ k g}^{-1}$} & {$[\mathbf{C d}] \mathbf{~ m g ~ k g}^{-1}$} & {$[\mathbf{N i}] \mathbf{~ m g ~ k g}^{-1}$} \\
\hline 1 & 702,00 & 208,50 & 329,00 \\
\hline 2 & N/D & N/D & 1389,00 \\
\hline 3 (NPK) & 1915,00 & N/D & 4886,26 \\
\hline
\end{tabular}




\begin{tabular}{|c|c|c|c|}
\hline 4 & 13,27 & 81,70 & 2264,00 \\
\hline 5 & 13,27 & N/D & 515,70 \\
\hline 6 (NPK) & N/D & 6,20 & 5,43 \\
\hline 7 (NPK) & N/D & 6,72 & 6,43 \\
\hline 8 (NPK) & 353,50 & 9,05 & 38,55 \\
\hline
\end{tabular}

N/D: não detectado

O Quadro 2 apresenta valores orientadores com os teores máximos permitidos para cádmio e níquel em fertilizantes conforme Malavolta e Moraes (2006).

Quadro 2. Limites máximos de metais pesados tóxicos contidos em fertilizantes minerais.

\begin{tabular}{|c|c|c|}
\hline Fertilizante & [Cd] $\mathbf{~ m g ~} \mathbf{~ k g}^{-1}$ & [Ni] $\mathbf{~} \mathbf{~} \mathbf{~ k g}^{-1}$ \\
\hline NPK & 0,75 & não permitido \\
\hline mistura mineral & 20,00 & não permitido \\
\hline
\end{tabular}

Fonte: Malavolta e Moraes, 2006 (modificado).

Da observação dos dois quadros, é possível perceber que o metal cádmio, quando detectado na amostra de fertilizante, encontra-se em quantidades muito superiores às permitidas, por vezes, em concentração dez vezes maior.

Com relação ao metal níquel, a situação é muito preocupante, pois, não deveria haver traços desse metal nos fertilizantes, pelo menos não nas duas categorias analisadas.

Deve se destacar o fato de que esses metais são disponibilizados aos solos durante a aplicação dos fertilizantes, e destes, aos cultivares e acabam, com certeza, adentrando o organismo humano. Como salientado, na parte introdutória desse trabalho, esses metais são acumulativos e considerados carcinogênicos. Plicas et al. (2010) e Scotton (2011), determinaram teores elevados desses metais em solos cultivados com citrus nas regiões das cidades de São José do Rio Preto, Mogi Guaçu e Matão.

Quanto ao metal manganês não há, sequer, orientação sobre os teores máximos permitidos para fertilizantes. Existe uma recomendação do Governo do Estado de São Paulo (PRATES et al., 2011), para concentração máxima do metal em solos (Quadro 3). 
Quadro 3. Valores orientadores para manganês no solo para o Governo do Estado de São Paulo.

\begin{tabular}{|c|c|}
\hline Teor & $\mathrm{Mn}-(\mathrm{DTPA}) \mathrm{mg} \mathrm{dm}^{-3}$ \\
\hline baixo & $0-1,2$ \\
\hline médio & $1,3-5,0$ \\
\hline alto & $>5,0$ \\
\hline
\end{tabular}

Fonte: Prates et al. (2011)

Mesmo que as unidades de concentração sejam diferentes ( $\mathrm{mg} \mathrm{kg}^{-1}$ nesse trabalho), percebe-se que o grau de tolerância à presença do metal no solo não é elevado. Quantidade excessiva de manganês é prejudicial ao organismo humano, como explicitado na porção inicial dessa pesquisa.

Estudos têm revelado altas dosagens de manganês em amostras de solos não cultivados, no Estado de São Paulo, em especial, na região de São José do Rio Preto. A presença do metal nesses solos tem sido atribuída á liberação de produtos de combustão e/ou na forma de aditivos aos combustíveis. Os teores determinados chegam a ser várias vezes superiores ao limite máximo apresentado pelo Quadro 3 (PRATES, 2011, PRATES et al., 2011, SOUZA, 2012, SGOTTI, 2012 e PAGANINI, 2012).

Cabe reforçar que a informação acima se refere a solos não cultivados. Dessa forma, é plausível supor que as dosagens de manganês, e também de cádmio e níquel, sejam ainda maiores em solos utilizados no plantio, uma vez que, nos mesmos, são utilizados insumos agrícolas, tais como defensivos e fertilizantes, que contem esses metais em suas formulações.

Há, também, trabalhos que demonstram que a lixiviação de manganês e cádmio dos solos é eficiente durante os períodos de chuvas. Nesse processo os metais são transportados, pela percolação das águas, até porções mais profundas do subsolo, podendo atingir os aquíferos subterrâneos. Com relação aos mananciais superficiais existe a possibilidade de seu acúmulo naqueles que são represados e cujas águas são utilizadas para abastecimento urbano (MACEDO, 2009, GONÇALVES, 2009, CABRAL, 2011, SILVEIRA, 2013 e MAGALHÃES, em preparação).

\section{CONCLUSÃO}


As análises químicas realizadas, nesse estudo, para a determinação das dosagens dos metais cádmio, níquel e manganês em amostras de fertilizantes comerciais, de livre acesso, demonstraram que os dois primeiros metais se encontram, na maioria das vezes, em quantidades altamente proibitivas na formulação desses insumos. Para o manganês não há subsídios técnicos que permitam essa avaliação, mas, devido aos altos teores encontrados desse metal, é muito provável que, também, sua concentração se encontre em demasia, nesses produtos. Todos os metais analisados são potencialmente tóxicos ao ser humano. O cádmio e o níquel são considerados carcinogênicos. O manganês é prejudicial em doses elevadas. É preocupante a sua disponibilização em excesso para os solos, desses para as plantas e, por fim, para o nosso consumo. É, também, preocupante, o fato de serem remobilizados, com certa facilidade, pelas águas pluviais podendo contaminar os mananciais subterrâneos e superficiais. Dessa forma, há a necessidade de mais trabalhos de avaliação dessa situação que envolvam, inclusive, análises sistemáticas de águas, em especial, daquelas represadas para abastecimento urbano. É necessário, também, um controle maior, eficaz e em curto prazo, das autoridades competentes junto à indústria desses aditivos. A não observância desses itens, com certeza, conduzirá a um incremento na incidência de patologias graves em habitantes de comunidades que consumam esses alimentos e que utilizem essas águas.

\section{REFERÊNCIAS}

BAIRD, Colin. Química Ambiental. 2ed. Porto Alegre. Editora Bookman. 622 p. 2002.

CABRAL, Débora Cristina Alves. Estudo da adsorção de Cádmio em um solo de citricultura na cidade de Neves Paulista, região de São José do Rio Preto. Monografia de Conclusão de Curso. Universidade Estadual Paulista. 2011.

CARDOSO Luiza Maria Nunes; CHASIN, Alice Aparecida da Matta. Ecotoxicologia do Cádmio e Seus Compostos. Série Cadernos de Referência Ambiental, v.6. Centro de Recursos Ambientais (CRA), Salvador, BA, 2001. 
CAMPOS, Mari Lucia et al. Determinação de cádmio, cobre, cromo, níquel, chumbo e zinco em fosfatos de rochas. Pesquisa Agropecuária Brasileira, Brasília, v. 40, n. 4, p. 362-367, abr. 2005.

DAMIÃO, Ana; RAMOS, Ana. Manganês. Trabalho realizado no âmbito da disciplina de Toxicologia e Análises Toxicológicas I no ano letivo 2004/05. Faculdade de Farmácia da Universidade do Porto, Portugal. Disponível em:

http://www.ff.up.pt/toxicologia/monografias/ano0405/manganes/manganes.htm.

Acesso em: 18/12/2012

FIGUEIREDO-FERNANDES, Antonio. et al. Histopathological changes in liver and gill epithelium of Nile tilapia, Oreochromis niloticus, exposed to waterborne copper. Pesq. Vet. Bras. 27(3):103-109, março 2007. Disponível em:

http://www.scielo.br/pdf/pvb/v27n3/04.pdf. Acesso em: 15/12/2012

GONÇALVES, Laís Maria. Análises Químicas e Determinação de Metais em Fertilizantes e Solo de Cultivo de Laranja. Monografia de Conclusão de Curso. Universidade Estadual Paulista. 2009.

GONÇALVES, Veridiana Cardozo et al. Adsorção de cádmio em solos cauliniticos. Revista da FZVA. Uruguaiana, v.15, n.2, p. 01-10. 2008

GUERREIRO, Luis. Alimentação Viva. Disponível em:

http://alimentacaoviva.blogspot.com/2007/04/luis-guerreiro-titulo-de curriculum.html. Acesso em: 15/12/2012.

MACEDO, Rafael dos Santos. Caracterização Física e Química de Solo de Plantação de Laranja da Região de São José do Rio Preto e Estudo da Adsorção de Cádmio no Horizonte Superficial. Monografia de Conclusão de Curso. Universidade Estadual Paulista. 2009. 
MAGALHÃES, Laisa Paula. Teores elevados de manganês observados em amostras de solos coletadas em um trecho da Rodovia SP-310 durante período de estiagem. Monografia de Conclusão de Curso. Universidade Estadual Paulista. (em preparação)

MALAVOLTA, Eurípedes; MORAES, Milton Ferreira., Sobre a sugestão dos metais pesados tóxicos em fertilizantes e sobre a portaria 49 de 25/04/2005 da Secretaria de Defesa Agropecuária do Ministério da Agricultura, Pecuária e Abastecimento. Informações Agronômicas ํo 114 - junho/2006. Disponível em:

http://www.inpofos.org/ppiweb/brazil.nsf/87cb8a98bf72572b8525693e0053ea70/7759ddc6 878ca7eb83256d05004c6dd1/\$FILE/Page10-14-114.pdf. Acesso em abril/2013.

MANZINI, Flávio Fernando et al. Metais pesados: fonte e ação toxicológica. Fórum Ambiental da Alta Paulista, v. VI, p. 800-815, 2010.

MARTINS, Isarita; LIMA, Irene Videira. Ecotoxicologia do manganês e seus compostos. Série Cadernos de Referência Ambiental, v.7, Centro de Recursos Ambientais (CRA), Salvador, BA, 2001.

MENEZES FILHO, José Antonio. Níveis elevados de manganês e déficit cognitivo em crianças residentes nas proximidades de uma metalúrgica ferro-manganês na Região Metropolitana de Salvador, Bahia. Rio de Janeiro, 2009. 148p. Tese (Doutorado em Ciências na área de Saúde Pública e Meio Ambiente). Escola Nacional de Saúde Pública Sérgio Arouca.

OLIVEIRA, Teógenes Senna; COSTA, Liovando Marciano. Metais pesados em solos de uma topolitosseqüência do Triângulo Mineiro. Rev. Bras. Ciênc.

Solo vol.28 no.4 Viçosa July/Aug. 2004. Disponível em: http://www.scielo.br/scielo.php?pid=S010006832004000400018\&script=sci_arttext. Acesso em: 15/12/2012 
PAGANINI, Éder Ramos. Determinação do teor de manganês em amostras do solo de São José do Rio Preto (SP). Monografia de Conclusão de Curso. Universidade Estadual Paulista. 2012.

PLICAS, Lídia Maria de Almeida et al. Teores elevados de cobre e níquel em dois solos cultivados com laranja no Estado de São Paulo. Fórum Ambiental da Alta Paulista, v. VI, p. 816-829, 2010.

PRATES, Helena Magalhães. Avaliação do teor de manganês solúvel e disponível em amostras de solos do Estado de São Paulo. Monografia de Conclusão de Curso. Universidade Estadual Paulista. 2011.

PRATES, Helena Magalhães et al. Teores elevados de manganês em amostras de solos. in FORUM AMBIENTAL DA ALTA PAULISTA, 7. Tupã, São Paulo. Periódico Eletrônico v. 7, ํㅜ 12, p. 1563-1574. 2011.

SCOTTON, Tathiane. Avaliação dos teores dos metais cádmio e níquel em amostras de solos e de fertilizantes. Monografia de Conclusão de Curso. Universidade Estadual Paulista. 2011.

SGOTTI, Juliene Médis. Teores elevados de manganês observados em amostras de solos coletadas em um trecho da Rodovia SP-310. Monografia de Conclusão de Curso. Universidade Estadual Paulista. 2012.

SILVA, Fábio Cesar. Manual de análises químicas de solos, plantas e fertilizantes. EMBRAPA Solos e EMBRAPA Informática Agropecuária, 3ª edição, 1999. 370p.

SILVEIRA, Bruno Saravali. Determinação do teor de manganês disponível em amostras de solos coletadas em vias públicas durante período de estiagem. Monografia de Conclusão de Curso. Universidade Estadual Paulista. 2013. 
SOUZA, Rodolfo Pereira. Determinação do teor de manganês em amostras de solos e do teor total desse metal em fertilizante. Monografia de Conclusão de Curso. Universidade Estadual Paulista. 2012. 